\title{
TREATMENT OF RECURRENT ANTERIOR SHOULDER DISLOCATION WITH BRISTOW-LATARJET PROCEDURE
}

\section{TRATAMENTO DA LUXAÇÃO ANTERIOR RECIDIVANTE DO OMBRO PELA TÉCNICA DE BRISTOW-LATARJET}

\author{
arnaldo amado Ferreira Filho ${ }^{1}$ (D), Eduardo angel Malavolta ${ }^{1}$ (D), Mauro Emillo Conforto Gracitelli ${ }^{1}$ (D), \\ Jorge Henrique Assunção ${ }^{1}$ (D), Fernando Brandão de ANDrade e Silva ${ }^{1}$ (D), Raul Bolliger Neto ${ }^{1}$ (D), \\ AMÉRICO ZOPPI FILHO ${ }^{1}$ (D), ARNALDO AMADO FERREIRA NETO ${ }^{1}$ (D)
}

1. Universidade de São Paulo, Medical School, Hospital das Clínicas, São Paulo, SP, Brazil

\section{ABSTRACT}

Objectives: To describe the clinical and radiographic results of patients with traumatic recurrent anterior shoulder dislocation treated with the Bristow-Latarjet procedure. Methods: Retrospective case series including 44 patients (45 shoulders) who underwent the Bristow-Latarjet procedure. The graft was fixed "standing" in $84 \%$ of the shoulders, and "lying" in 16\%. Results: The follow-up was $19.25 \pm 10.24$ months. We obtained $96 \%$ of good results, with 2 recurrences presented as subluxation. Graft healing occurred in $62 \%$ of cases. The graft was positioned below the glenoid equator in $84 \%$ of the cases, and less than $10 \mathrm{~mm}$ from its edge in $98 \%$. The external rotation had a limitation of $20.7^{\circ} \pm 15.9^{\circ}$, while the internal rotation was limited in $4.0^{\circ} \pm 9.6^{\circ}$. The limitation of rotation and the position of the graft ("standing" or "lying") did not correlate with graft healing ( $p>0.05)$. Bicortical fixation was positively correlated with healing $(p<0.001)$. Conclusion: The Bristow-Latarjet technique is indicated for the treatment of recurrent anterior dislocations and subluxations of the shoulder. It is a safe treatment method, which can be used in people with intense physical activity. Limiting shoulder mobility does not prevent patients from returning to their usual occupations. Level of Evidence IV, Case series.

Keywords: Shoulder Dislocation. Joint Instability. Orthopedic Procedures. Tendon Transfer. Coracoid Process.
RESUMO

Objetivos: Descrever os resultados clínicos e radiográficos do tratamento da luxação anterior recidivante traumática do ombro pela técnica de Bristow-Latarjet. Métodos: Série de casos retrospectiva, incluindo 44 pacientes (45 ombros) submetidos à técnica de Bristow-Latarjet. O enxerto foi fixado "em pé" em $84 \%$ dos ombros, e "deitado" em 16\%, utilizando 1 parafuso metálico. Resultados: O seguimento foi de 19,25 \pm 10,24 meses. Obtivemos $96 \%$ de bons resultados, sendo 2 recidivas sob a forma de subluxação. A consolidação ocorreu em $62 \%$ dos casos. 0 enxerto foi posicionado abaixo do equador da glenoide em $84 \%$ das vezes, e a menos de $10 \mathrm{~mm}$ da sua borda em 98\%. A rotação externa apresentou limitação de $20,7^{\circ} \pm 15,9^{\circ}$, enquanto a rotação interna $4,0^{\circ} \pm 9,6^{\circ}$. A limitação das rotações e a posição do enxerto ("em pé" ou 'deitado") não se correlacionaram com a consolidação do enxerto. A fixação bicortical correlacionou-se positivamente com a consolidação. Conclusões: A técnica de Bristow-Latarjet está indicada para o tratamento da instabilidade anterior recidivante do ombro. É um método de tratamento seguro, que pode ser utilizado em pessoas com atividade física intensa. A limitação da mobilidade do ombro não impede os pacientes de voltarem às suas ocupações habituais. Nível de Evidência IV, Série de casos.

Descritores: Luxação do Ombro. Instabilidade Articular. Procedimentos Ortopédicos. Transferência Tendinosa. Processo Coracoide.

Citation: Ferreira Filho AA, Malavolta EA, Gracitelli MEC, Assunção JH, Andrade e Silva FB, Bolliger Neto R, et al. Treatment of recurrent anterior shoulder dislocation with Bristol-Latarjet Procedure. Acta Ortop Bras. [online]. 2021;29(1):39-44. Available from URL: http://www.scielo.br/aob.

\section{INTRODUCTORY NOTE}

Dr. Arnaldo Amado Ferreira Filho defended his doctoral dissertation in 1984, but the results were never published in scientific journals, and the dissertation is not available on digital platforms. Thus, although he is a pioneer of Shoulder and Elbow Surgery in Brazil, and his knowledge has been fundamental for subsequent generations of orthopedists, the citation of his results in articles and dissertations was very difficult. The objective of this study is to describe the clinical and radiographic results of the treatment of recurrent anterior shoulder dislocation using the Bristow-Latarjet technique, based on Dr. Arnaldo Amado Ferreira Filho's doctoral dissertation, carried out in 1984. The essay intended to be the most accurate to the original, making minimal adaptations and respecting the author's writing style and the formatting of the usual text at the time.

All authors declare no potential conflict of interest related to this article.

The study was conducted at Hospital das Clínicas.

Correspondence: Eduardo Angeli Malavolta. Rua Dr. Ovídio Pires de Campos, 333, 3rd floor, Cerqueira Cesar, São Paulo, SP, Brazil, 05403010. eduardomalavolta@gmail.com 


\section{INTRODUCTION}

The great mobility of the shoulder requires precise and complex integrated mechanisms of sliding and dynamic stabilization whose vulnerability is the price paid by man in order to be able to fully enjoy it. Traumas and predispositions of various natures can break this functional harmony, causing the loss of joint congruence whose recurrence is studied in the area of scapular instabilities.

Numerous surgical techniques have been proposed for the treatment of recurrent anterior dislocation of the shoulder and, among them, the bone block by pedicled graft of the coracoid process near the anterior edge of the glenoid described by Latarjet ${ }^{1}$ and Helfet stands out. ${ }^{2}$ This study describes the clinical and radiographic results of the treatment of recurrent anterior shoulder dislocation by the Bristow-Latarjet technique.

\section{MATERIALS AND METHODS}

This study sample is composed of 44 patients, with documentation referring to 45 shoulders. The mean age at the time of surgery was $23.74 \pm 7.16$ and in the first episode of dislocation $18.81 \pm 5.15$. In total, 38 patients (86\%) were male, six of them (14\%) presented epilepsy, and 35 (80\%) had traumatic dislocations. The number of recurrences was one to five for nine patients (20\%), six to 10 for 11 patients (24\%) and higher than 10 in 25 (56\%) patients. A total of 36 patients (82\%) practiced sports, eight (18\%) at the amateur competitive level, 28 (64\%) as recreational activity and most patients practiced more than one modality.

\section{Clinical examination}

Our patients were examined many days after the dislocation episodes and - as always happens in these cases - the clinical examination gave us little information. None of the patients presented pain on palpation or movement, alteration of muscle trophism, peripheral neurovascular injuries or alterations in joint mobility. All patients presented a positive apprehension test and three (7\%) presented ligament laxity according to Carter and Wilkinson ${ }^{3}$ criteria modified by Beighton and Horan. ${ }^{4}$

\section{Radiographic examination}

Radiographs were performed at anteroposterior incidences in external and internal rotation of $60^{\circ}$ and lateral view. We could observe the posterolateral injury of the humeral head in 43 shoulders (96\%) and periarticular calcifications in five (11\%).

\section{Intraoperative findings}

The described anatomopathological injuries refer to 38 (84\%) of the 45 operated shoulders, since in seven medical records the precise information was not found. We observed two cases (5\%) of partial rupture of the upper edge of the subscapularis tendon and loose bodies in nine shoulders (24\%). The joint capsule was redundant in all cases, and there was capsule-periosteal disinsertion at the level of the neck of scapula and glenoid labrum injury in 37 cases (97\%). Marginal fracture of the glenoid edge was observed in two cases (5\%), while variable erosion and eburnation of the scapular neck were observed in 37 shoulders (97\%).

\section{Surgical technique}

The general anesthesia was applied by tracheal inhalation and intravenous infusion. The patients were positioned in horizontal supine position with a cushion placed under the scapular region of the side to be operated.

\section{Operative times:}

1. Deltopectoral incision about eight $\mathrm{cm}$ long, from the lower edge of the clavicle.
2. Identification of the cephalic vein in the deltopectoral groove and displacement of the cephalic vein in the medial direction along with a narrow parallel band of fibers of the deltoid muscle in order to protect it.

3. Exposure, via transdeltoid, of the coracoid process with the insertions of pectoralis minor, coracoacromial ligament, conjoint tendon, and muscle bellies of the short biceps and the coracobrachialis.

4. Osteotomy of the coracoid process about two $\mathrm{cm}$ from its apex with chisel and hammer and release of the bone fragment by sectioning the fibers of the pectoralis minor and the coracoacromial ligament inserted on it.

5. Hemostasis of the bloody area remaining from the coracoid process with bone wax.

6. Dissection of the coracobrachialis muscles and the short biceps in the caudal direction to the lower edge of the subscapularis muscle without exceeding it, to avoid the risk of injury to the musculocutaneous nerve that, about six $\mathrm{cm}$ below the coracoid process, penetrates into the muscular belly of the coracobrachialis muscle.

7. Perforation of the pedicled bone graft obtained, from its base to its apex (graft "standing"), with a quadrangular section awl to ease screw passage. When the coracoid process is narrow with a small cross-section area insufficient to contain the screw, the perforation should be performed in a transverse direction, in the smallest diameter (graft "lying") as described by Latarjet. ${ }^{1}$

8. Inspection of the subscapularis muscle and opening of the subscapularis muscle at the level of its median part, with an incision parallel to its fibers initiated near the lesser tubercle of the humerus. The incision extending from the tendon to the muscular belly should be long enough to allow a good separation of its edges and easy access to the underlying scapulohumeral joint. As the joint capsule is always adhered to the entire extension of the tendon, it was opened simultaneously with the opening of the tendon, then prolonging the capsular incision parallel to the muscle belly.

9. Careful exploration of joint structures.

10. Identification of the passage site of the humerus head, marked by capsule-periosteal disinsertion and erosion of the glenoid edge.

11. Excision of the glenoid labrum or its remains and the reactional scar tissue existing in the neck of scapula, near the edge of the glenoid, in order to clean the area where the graft will be placed. The neck of scapula is most often white and irregular as a consequence of the friction caused by the head of the humerus.

12. Cruentation, without chopping the cortical, with scalpel, curette or chisel, for graft placement.

13. Perforation of the neck of scapula, with electric punch and drill diameter, a graduation below that normally used, also transfixing the posterior cortical, as parallel as possible to the plane of the articular surface. The distance between the screw fixation hole and the glenoid edge should allow, after graft fixation, a perfect continuity between the graft and the plane of the articular surface.

14. Verification, with the appropriate meter, of the neck of scapula width to allow the choice of a screw of sufficient length to transfix the posterior cortical.

15. Firm fixation of the graft to its place, with the available screw, preferably cancellous screws, taking care that the edge of the graft is in continuity with the edge of the glenoid, and it should not exceed it or be away from it. When placed "standing," the coracoid process was fixed with its posterior-inferior face, slightly concave, facing the head of the humerus. A washer can be used to increase the support area of the screw over 
the graft, strengthening its pressure resistance and avoiding friction between the head of the humerus and the screw. In 38 shoulders (84\%) the graft was fixed "standing" and in seven shoulders (16\%) "lying"; the washer was used nine times.

16. With the arm in external rotation, the joint capsule and the subscapularis muscle were sutured with separated stitches.

17. Suture of the deltoid muscle with separate stitches.

18. Closure of the surgical incision with separate stitches in the subcutaneous cellular tissue and skin.

19. Immobilization

The main operative times are shown in Figure 1.

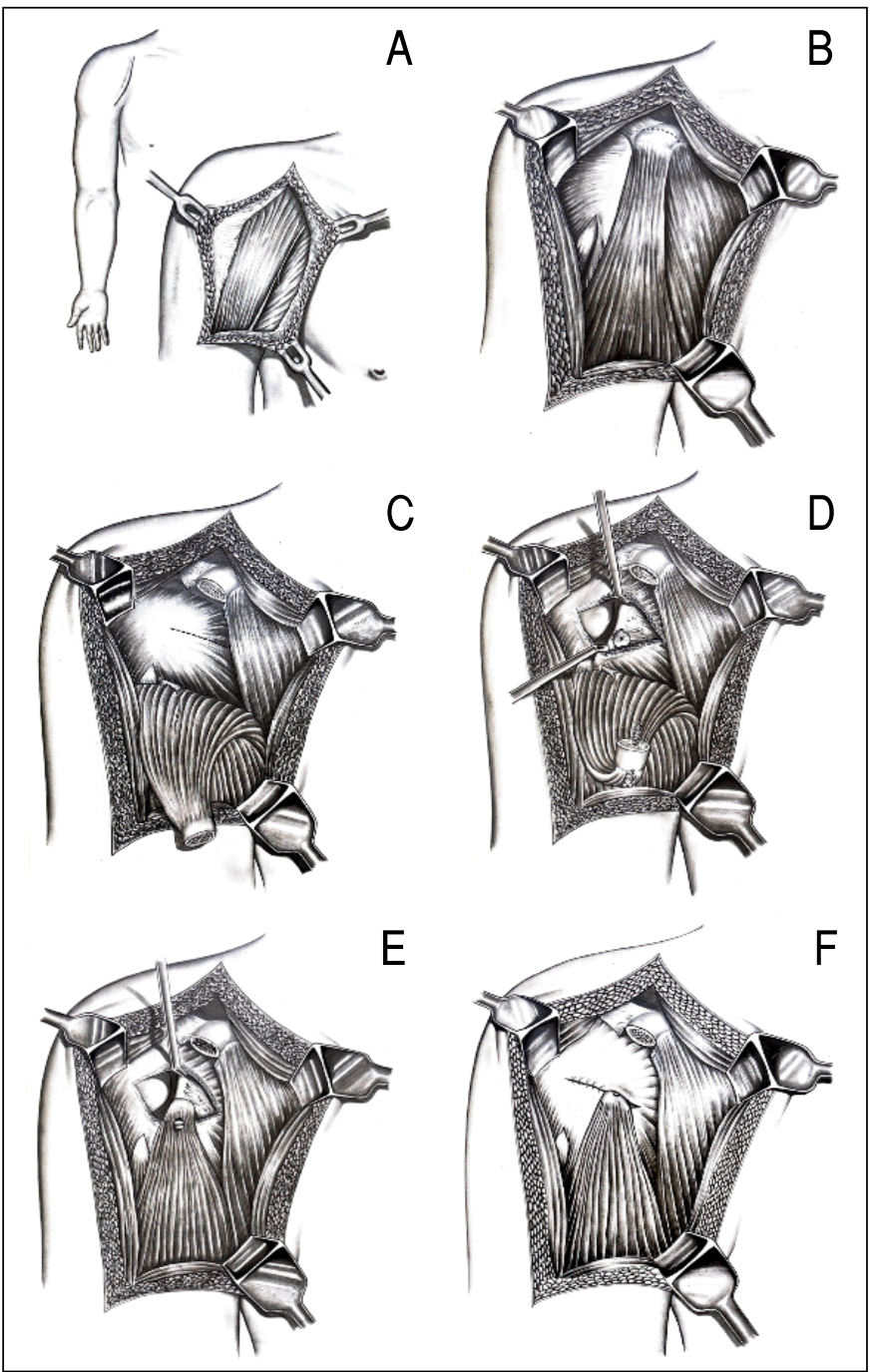

Figure 1. Surgical technique: A: Deltopectoral approach; B: Coracoid process and osteotomy site (dashed line); C: Osteotomy performed, with coracobrachialis muscles and short head of the biceps folded together with the graft, and incision site in the subscapularis muscle (dashed line); D: Exposure of the neck of scapula and head of the humerus, with the place for the graft prepared and coracoid process transfixed by the screw on its longitudinal axis; E: Graft fixed near the edge of the glenoid; $F$ : suture of the subscapularis muscle laterally to the graft.

\section{Postoperative}

Thoracobrachial bandage was maintained for 21 days, with weekly changes for inspection of the surgical wound and patient' hygiene.
The stitches were removed on the 10th day. The patients were medicated exclusively with analgesics. The length of hospital stay ranged from two to 13 days, with an average stay of three days. On the 22nd day, rehabilitation was initiated, which consisted of passive pendulum exercises followed by isometric and isotonic active exercises aimed to strengthening muscle and restoring joint mobility. From the 90th day on, the return to sports activities was both allowed and also encouraged.

\section{Evaluation criteria}

\section{Criteria based on clinical data}

1. Joint stability. Joint stability was assessed by recurrence of dislocation (being considered recurrence both episodes of dislocation and subluxation) and by the seizure test. The result was categorized as good (no recurrence and negative apprehension test), regular (no recurrence and positive apprehension test) and bad (with recurrence).

2. Presence of spontaneous, palpation-related or movement-related pain

3. Presence of alteration in muscular trophism

4. Presence of vasculonervous lesions

5. Limitation of active joint mobility. The amplitude of external rotation, internal rotation, and abduction was measured, and the respective limitations were estimated.

6. Capability to practice sport The result was considered good (when the performance continued to be the same or became better) or bad (when the performance became worse).

7. Patients' opinion regarding the treatment performed. It was considered as good (when patients were satisfied) or bad (when they were not satisfied).

\section{Criteria based on radiographic data}

The criteria used by Hovelius et al. ${ }^{5}$ were largely adopted, and the following items were considered:

1. Behavior of the bone graft, observing whether there was resorption of the graft and healing of the graft in the neck of scapula.

2. Measurement of separation, in $\mathrm{mm}$, between the unconsolidated grafts and the neck of scapula, classified as fibrous union $(\leq 5 \mathrm{~mm})$ and small $(\leq 15 \mathrm{~mm}$ ) or large migration $(\geq 15 \mathrm{~mm})$

3. Measurement of the distance, in $\mathrm{mm}$, between the graft and the edge of the glenoid, classified as $<10 \mathrm{~mm}$ and $\geq 10 \mathrm{~mm}$.

4. Position of the graft in relation to the equator of the glenoid, considered as above the equator, at the equator, or below it.

5. Cortical fixation of the screw and stability of it, observing whether there was transfixation of the posterior cortical and displacement of the screw from its initial position.

6. Loosening of the graft by partial resorption without screw displacement

7. Injury to the head of the humerus by impact against the screw.

8. Postoperative osteoarticular lesions.

\section{Statistical Analysis}

The relationship between rotation limitation and graft consolidation was analyzed by Student's $t$-test. The limitation of external rotation was also correlated with the postoperative follow-up time by regression analysis. By Fisher's test, they were confronted:

a. consolidation of the graft and its position ("standing" or "Iying");

b. loosening of the graft and its position ("standing" or "lying");

c. graft consolidation and cortical screw fixation (mono or bicortical); 
d. screw displacement and cortical screw fixation (mono or bicortical).

\section{RESULTS}

The patients had a mean follow-up time of $19.25 \pm 10.24$ months, ranging from nine to 84 months. Follow-up time was longer than 12 months in 36 cases (76\%).

\section{Clinical analysis}

Regarding joint stability, we obtained $96 \%$ of good results (43/45) and $4 \%$ of bad results (2/45). The two cases of recurrence occurred as subluxation. One of the patients presented subluxation four years after surgery, after a sudden movement caused by an electrical discharge. The patient did not suffer any restriction in their activities, latter returning to soccer and swimming practice. Another patient presented subluxation 18 months after surgery, as a result of a violent trauma during a rugby match, with two other episodes in the following days, one sleeping with shoulder in abduction and maximum external rotation, and another playing capoeira. There were no other episodes after, remaining asymptomatic for two years. He regularly practices swimming and capoeira but has quit rugby. The apprehension test was negative on all shoulders, including those who suffered recurrence.

Three patients complained of persistent pain (6.7\%). The first one had little intense pain at movements, the second persistent pain on palpation and movements, and sometimes spontaneous pain. The third, in addition to pain similar to the previous one, complained of crackling and limitation of the range of motion, preventing the patient from exercising the usual occupations.

We observed mild muscle hypotrophy in five patients (11\%), mainly in the deltoid and biceps muscles, with no apparent decrease in muscle strength.

No patient presented local or distance vasculonervous changes. The limitation of external rotation ranged from $0^{\circ}$ to $70^{\circ}$, with an average of $20.7^{\circ} \pm 15.9^{\circ}$. The internal rotation presented an average limitation of $4.0^{\circ} \pm 9.6^{\circ}$, ranging from $0^{\circ}$ to $40^{\circ}$.

Out of the 36 patients (37 shoulders) who practiced sports, 32 (89\%) presented good result and four (11\%) bad results.

According to the patients' opinion, 41 (93\%) presented good result and three $(7 \%)$ bad. The three patients declared that they were dissatisfied with the surgery, since they presented persistent pain when moving the operated shoulder.

\section{Radiographic analysis}

The graft consolidated in 28 shoulders (62\%), absence of consolidation in 16 (36\%), and absorption in one (2\%). Out of the 16 grafts that did not consolidate, in 10 the screw was displaced along with the graft and in six there was no displacement of the screw, but the graft developed a central area of absorption. In 14 (31\%) shoulders there was fibrous union, in one small migration and in another large migration.

The graft was fixed at a distance greater than $10 \mathrm{~mm}$ from the edge of the glenoid in only 1 shoulder (2\%). In three shoulders (7\%) the graft was positioned above the equator of the glenoid, in four (9\%) at the equator and in 38 (84\%) below it. Bicortical fixation was obtained in 38 shoulders (84\%), and in seven of these the screw exceeded the posterior cortical more than five $\mathrm{mm}$. In total, 10 screws (22\%) were displaced, and an osthelysis of $1 \mathrm{~mm}$ or more was observed around them. In two shoulders (4\%) the screw was bumped with the head of the humerus because it was fixed excessively oblique. In Figure 2, we observed cases with correct positioning of the graft and screw.

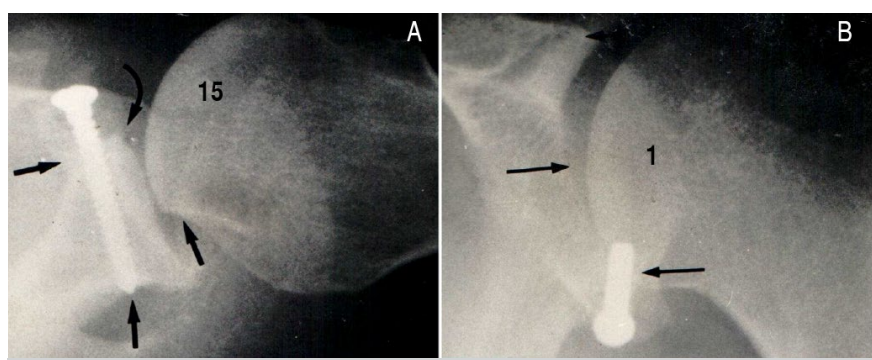

Figure 2. Radiographs demonstrating adequate positioning of the graft and screw. A: Graft near the edge of the glenoid, consolidated, with adequate size and angulation screw; B: Graft positioned below the equator of the glenoid.

In Figure 3, we exposed some errors of surgical technique (medialized graft, oblique and long screw, and graft positioned above the equator of the glenoid).

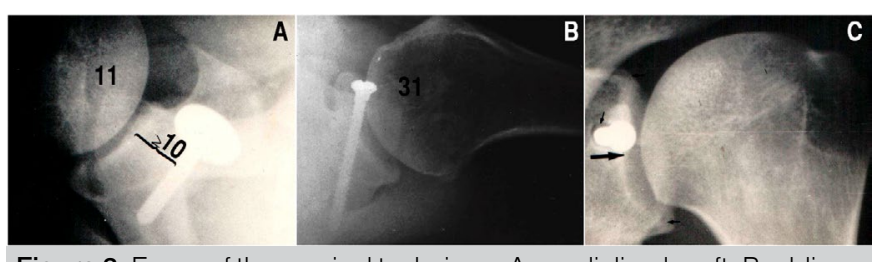

Figure 3. Errors of the surgical technique: A: medialized graft; B: oblique and long screw; C: graft positioned above the equator of the glenoid.

In Figure 4, we highlight some of the complications visualized by radiography (absence of consolidation, osteolysis around the screw and displacement of the screw).

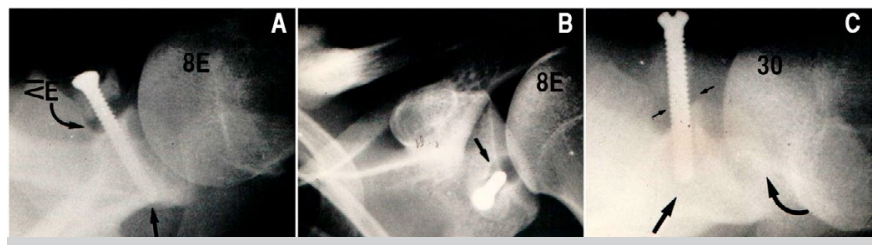

Figure 4. Surgical complications. A: absence of consolidation; $\mathrm{B}$ : osthelysis around the screw; C: screw displacement.

\section{Statistical analysis}

The limitation of external and internal rotation did not correlate with graft consolidation ( $p=0.852$ and $p=0.512$, respectively). Similarly, the position of the graft ("standing" or "lying") did not correlate with bone consolidation or graft loosening ( $p=0.884$ and $p=0.391$, respectively). Bicortical fixation presented a statistically significant correlation with consolidation $(p<0.001)$ and with lower screw displacement index $(p=0.003)$. The limitation of external rotation is correlated with the follow-up time, decreasing over time $(p<0.05)$.

\section{Complications}

We observed one case (2\%) of subcutaneous hematoma (drained on the fifth postoperative day), persistent pain in one case (2\%), probably caused by a reaction to the screw; by removing it, the pain disappear and two cases (4\%) of humeral head injury by impact against the screw that was placed excessively oblique, exceeding the edge of the glenoid. Joint pain, abduction limitation, and joint crackling decreased considerably after screw removal in both patients. 


\section{DISCUSSION}

The presence of $80 \%$ of traumatic cases in our series does not differ from what is reported in the literature..$^{5-7}$ Similarly, the prevalence in young adults - with most of the first episodes happening until the age of 20 , and predominantly in males - is also presented by other authors. ${ }^{5,7}$ The practically equal occurrence between dominant and non-dominant side - observed in this study is described by Hovelius et al., ${ }^{5}$ but this results disagree with Hill et al., ${ }^{7}$ where shoulder dislocation is more frequent on the dominant side. Out of our patients, only $7 \%$ had ligament laxity, a small incidence compared to the $24 \%$ of Hill et al. ${ }^{7}$. On the other hand, the incidence of epilepsy (14\%) is higher than those of other authors, who report 1 to $7 \%$.,

We found capsular and labral disinsertions in $97 \%$ of the shoulders. This high incidence is described by other authors, ranging from $66 \%$ to $99 \% .^{6-10}$ Lesions of the subscapularis muscle can be observed as looseness or structural lesions. ${ }^{6,10,11}$ De Palma et al. ${ }^{11}$ found this condition on all shoulders, while McLaughlin ${ }^{10}$ and Rowe et al. ${ }^{6}$ in only $8 \%$ and $10 \%$, respectively. We believe that the disparity of opinions lies in the subjectivity of the evaluation. In our series, we did not quantify the subscapularis laxity, but only the structural injuries, found in $5 \%$ of the cases. The eburnation of the neck of the scapula is observed in 21 to $87 \%$ 6,9,12 of the cases, and the glenoid edge may be fractured in $13-44 \%$ of the cases. $^{6-8}$ In our series, we observed eburnation of the neck of scapula and erosion of the glenoid edge in $97 \%$ of cases, and glenoid edge fracture in $5 \%$. Loose bodies were found in $20 \%$ of the shoulders, and the presence of this finding ranges from 2 to $31 \%$ in the literature. ${ }^{6,7,11,12}$

The posterolateral injury or "typical defect," as it was previously called, or Hill-Sachs lesion, as English-speakers authors insist on calling it, has an incidence ranging from $45 \%$ to $100 \%$ of cases. ${ }^{6-8}$ Perhaps the reasons for such discordant results are the need for special incidences in small lesions, which require a broad surgical approach, unnecessary in most surgical techniques for their exposure. We observed the injury as a radiographic finding in $96 \%$ of the shoulders and only few times we were able to palpate it during the surgical process.

Several original surgical techniques, or their variations, have been proposed for the treatment of recurrent anterior shoulder dislocation. De Palma et al. ${ }^{11}$ grouped the surgeries into five categories: tendon-ligament and labial plastics, tendon transfers, bone blocks, corrective osteotomies, and tendon-suspensions. The dynamic blocking function of the coracoid process, originally considered a static bone block, ${ }^{1,11}$ started to be valued, ${ }^{13,14}$ at the expense of transplanted muscles and being complemented by the fixation of the lower half of the subscapularis. In addition to these actions, recalls D'Angelo, ${ }^{15}$ the graft fills the bone failure in the anterior edge of the glenoid, increases the area of articular surface, and prevents the posterolateral lesion from engaging on the glenoid failure.

In most cases, we did not put the graft in its smallest diameter ("lying" because we considered that the graft resists less to the compression force. Similarly, we do not pierce the graft in situ, as most authors do, ${ }^{5,13,14}$ because there is a risk of miss-positioning the drill. Perhaps this is the reason for the high incidence (7 to 14\%) of intraoperative fractures reported by other authors, 5,7 complications that do not exist in our series. We also did not shorten the subscapularis muscle, as other surgeons did. ${ }^{1,13}$

Mostly, postoperative pain is associated to problems directly related to the screw or graft. ${ }^{16}$ The screw may be protruding beyond the edge of the glenoid, for it was placed obliquely in relation to the articular surface, and in these conditions, it collides against the humeral head, harming it, a fact observed in two of our patients. The loose, excessively long, dislocated or fractured screw can also be a cause of pain, a fact that occurred in one of our patients. Any postoperative painful manifestation should be investigated carefully.

The limitation of external rotation is recognized by many as one of the significant factors that prevent recurrence of dislocations and some surgical techniques deliberately aim to achieve it. It is observed in virtually all statistics, even when procedures are not intended to obtain it. Although the Bristow-Latarjet technique is not based on the limitation of external rotation, it has been observed in a good percentage of operated shoulders. Only $16 \%$ of the cases in our series presented normal external rotation, and we observed an average of $20^{\circ}$ of limitation, similar to that described by Hovelius et al. ${ }^{5}$ but higher than other authors. ${ }^{7,14}$ Possibly, this difference originates from the external rotation evaluation technique. Practically all authors perform this technique with the arm at $0^{\circ}$ and $90^{\circ}$ of abduction, without fixing the scapula and the spine, or with the patient in supine position with the arms in abduction of $90^{\circ}$ and the palm of the hands placed on the nape. In our opinion, these are not the appropriate techniques, because they allow the movement of the scapula and spine, which improves the patient's performance. For this reason we evaluated not only the external rotation, but also the internal rotation, with the patient in horizontal ventral decubitus with the arm in abduction and the elbow flexed, both in $90^{\circ}$, fixing with one of the hands the scapula and the spine.

Abduction limitation has not been frequently reported in the literature, although it has been described by some authors. ${ }^{5,7}$ From our sample of patients, $7 \%$ had abduction limitation, and in two patients, the cause was attributed to the impact of the head against the screw. The limitation of internal rotation is also little reported, ranging from $3^{\circ}$ to $13^{\circ} .5,7$ We found this result in $20 \%$ of the patients, with a mean limitation of $4^{\circ}$, a result that we attributed to the examination technique aforementioned. For us, the fusion or not of the graft in the neck of scapula did not influence the limitation of both rotations, a finding similar to Nielson and Nielsen. ${ }^{17}$

Bristow-Latarjet surgery, like some other surgical procedure, has led to a worsening of the performance of throwers athletes whose dominant shoulder was compromised. 7,14 Out of four patients who were impaired, two had limitation of external rotation, and two of internal rotation and abduction. Three patients chose to quit the most violent modalities, without, however, quitting other sports. Comparing our results with those in the literature is difficult, not only because of our small number of competitive athletes, but also because we have treated few practitioners of throwing sports.

We observed graft fusion in the neck of scapula in $65 \%$ of the cases, a result similar to those of Hovelius et al., ${ }^{5}$ with $52 \%$. Hill et al. ${ }^{7}$ reported $96 \%$ consolidation, a result that may be related to the use of less accurate radiographic techniques. Bicortical fixation significantly influenced screw stability in the same way as graft fusion, results that confirm the opinion of Hovelius et al. ${ }^{5}$ The graft consolidation in the neck of scapula is achieved by firmly fixing the screw, that must be placed parallel to the plane of the articular surface, reach the posterior cortical exceeding it a few millimeters and the screw head must have the sufficient diameter to allow an ideal compression. A small washer can be used to meet this requirement.

For Bristow-Latarjet surgery achieve success, the graft cannot be exclusively consolidated, but it has to be correctly positioned on the anterior face of the neck of scapula, near the edge of the glenoid and below the equator. We observed that in $86 \%$ of the shoulders, the graft was placed below the equator, and in $98 \%$ of them, it was positioned less than $10 \mathrm{~mm}$ from the equator edge. This location is considered as the best by Hovelius et al. ${ }^{5}$ 
However, the placement of the graft at or above the equator did not affected stability.

Recurrences have been reported in almost all series of treatment of recurrent anterior dislocation of the shoulder, ranging from $0.7 \%{ }^{18}$ to $11 \%,{ }^{19}$ but some authors did not report them. ${ }^{13,17,20}$ Notably, Hill et al. ${ }^{7}$ and Hovelius et al., ${ }^{5}$ with 6 and $7 \%$ of subluxations, did not consider them as recurrences, and we do not agree with this statement. Our series demonstrated $4 \%$ recurrence, related to violent trauma.

\section{CONCLUSION}

The Bristow-Latarjet technique is indicated for the treatment of traumatic and non-traumatic anterior shoulder dislocations and subluxations. It is an easy and safe method that can be used in people who have great physical activity. The limitation of shoulder mobility observed in many cases does not prevent patients from returning to their usual occupations, as well as, in most of them, from playing sports with performance equal to that before the operation. The limitation of external rotation tends to decrease over time.

AUTHORS' CONTRIBUTIONS: Each author contributed individually and significantly to the development of this article. AAFF: data acquisition, analysis, and interpretation, substantial contribution in conception and design; EAM: writing, substantial contribution in conception and design; MECG: critical review, final approval of the manuscript version; JHA: critical review, final approval of the manuscript version; FBAS: critical review, final approval of the manuscript version; RBN: data acquisition, analysis and interpretation, substantial contribution to conception and design; AZF: data acquisition, analysis and interpretation, substantial contribution to conception and design; AAFN: critical review, final approval of the manuscript version.

\section{REFERENCES}

1. Latarjet M. Treatment of recurrent dislocation of the shoulder. Lyon Chir. 1954;49(8):994-7.

2. Helfet AJ. Coracoid transplantation for recurring dislocation of the shoulder. $J$ Bone Joint Surg Br. 1958; 40B(2):198-202.

3. Carter $\mathrm{C}$, Wilkinson J. Persistent joint laxity and congenital dislocation of the hip. J Bone Joint Surg Br. 1964;46:40-5.

4. Beighton $\mathrm{P}$, Horan F. Orthopaedic aspects of the Ehlers-Danlos syndrome. J Bone Joint Surg Br. 1969;51(3):444-53.

5. Hovelius L, Eriksson K, Fredin H, Hagberg G, Hussenius A, Lind B, et al. Recurrences after initial dislocation of the shoulder. Results of a prospective study of treatment. J Bone Joint Surg Am. 1983;65(3):343-9.

6. Rowe CR, Patel D, Southmayd WW. The Bankart procedure: a long-term end-result study. J Bone Joint Surg Am. 1978;60(1):1-16.

7. Hill JA, Lombardo SJ, Kerlan RK, Jobe FW, Carter VS, Shields CL, et al. The modification Bristow-Helfet procedure for recurrent anterior shoulder subluxations and dislocations. Am J Sports Med. 1981;9(5):283-7.

8. Palmer I, Widen A. The bone block method for recurrent dislocation of the shoulder joint. J Bone Joint Surg Br. 1948;30B(1):53-8.

9. Du Toit GT, Roux D. Recurrent dislocation of the shoulder; a twenty-four year study of the Johannesburg stapling operation. J Bone Joint Surg Am. 1956;38A(1):1-12.

10. McLaughlin LH. Recurrent anterior dislocation of the shoulder. Am J Surg 1956;99:628-32.
11. DePalma AF, Cooke AJ, Prabhakar M. The role of the subscapularis in recurrent anterior dislocations of the shoulder. Clin Orthop Relat Res. 1967;54:35-49.

12. Skogland LB, Sundt P. Recurrent anterior dislocation of the shoulder The Eden-Hybbinette operation. Acta Orthop Scand. 1973;44(6):739-47.

13. May VR Jr. A modified Bristow operation for anterior recurrent dislocation of the shoulder. J Bone Joint Surg Am. 1970;52(5):1010-6.

14. Lombardo SJ, Kerlan RK, Jobe FW, Caster VS, Blazina ME, Shields CL Jr. The modified Bristow procedure for recurrent dislocation of the shoulder. J Bone Joint Surg Am. 1976; 58(2):256-61.

15. D'Angelo D. Luxação recidivante anterior do ombro - tratamento cirúrgico [dissertation]. Rio de Janeiro: Faculdade de Medicina Universidade Federal do Rio de Janeiro; 1970.

16. Zuckerman JD, Matsen FA 3rd. Complications about the glenohumeral joint related to the use of screws and staples. J Bone Joint Surg Am. 1984;66(2):175-80.

17. Nielson AB, Nielsen K. The modified Bristow procedure for recurrent anterior dislocation of the shoulder. Results and complications. Acta Orthop Scand 1982;53(2):229-32.

18. De Anquin CE. Recurrent dislocation of the shoulder. J Bone Joint Surg Am. 1965;47:1085-94

19. Morrey BF, Janes JM. Recurrent anterior dislocation of the shoulder. Long-term follow-up of the Putti-Platt and Bankart procedures. J Bone Joint Surg Am. 1976;58(2):252-6.

20. Lipscomb AB. Treatment of recurrent anterior dislocation and subluxation of the glenohumeral joint in athletes. Clin Orthop Relat Res. 1975;(109):122-5. 
In the article entitled "TREATMENT OF RECURRENT ANTERIOR SHOULDER DISLOCATION WITH BRISTOW-LATARJET PROCEDURE" authored by Arnaldo Amado Ferreira Filho, Eduardo Angeli Malavolta, Mauro Emilio Conforto Gracitelli, Jorge Henrique Assunção, Fernando Brandão de Andrade e Silva, Raul Bolliger Neto, Américo Zoppi Filho, Arnaldo Amado Ferreira Neto, published in Revista Acta Ortopédica Brasileira (ACTA) vol. 29 n 1, 2021, page 39, DOI: http://dx.doi.org/10.1590/1413-785220212901242784, by request of the authors

Where it reads: Arnaldo Amado Ferreira Filho, Eduardo Angeli Malavolta, Mauro Emilio Conforto Gracitelli, Jorge Henrique Assunção, Fernando Brandão de Andrade e Silva, Raul Bolliger Neto, Américo Zoppi Filho, Arnaldo Amado Ferreira Neto

Read: Arnaldo Amado FERREIRA FILHO, Eduardo Angeli Malavolta, Mauro Emilio Conforto Gracitelli, Jorge Henrique Assunção, Fernando Brandão de ANDRADE E SILVA, Raul BOLLIGER NETO, Américo ZOPPI FILHO, Arnaldo Amado FERREIRA NETO 